115 AEROBIC EXERCISE TREATMENT OF JUVENILE OBESITY by Stephen S. Stone, George B. Dintiman, Ronald E. DeMeersman, Ann D. Fergueson, Mary T. Twigg, Lynn Weal, Michael F. Marte1li, and William W. Miller (Spon. by Marold M. Maurer). Division of Health and Physical Education \& the Department Pediatrics, Children's Medical Center, Virginia Commonwealth University - Medical College of Virginia, Richmond.

The effectiveness of aerobic exercise (Ex) and of behavioral, nutritional and social support (BNS) interventions were evaluated in 92 obese children in three primary public schools. In School A 28 children received 12 weeks of both F.x and BNS. In School B 42 children received only BNS. In School C 22 control children received no treatment. Before intervening there were no significant differences in group means for age, height, weight (Wt), triceps fatfold (Tri), or heart rate $10 \mathrm{sec}$ after exercise ( $H R$ ex). This table shows the mean group changes with intervention $(\Delta)$ and their statistical significance ( $* p<0.01)$

$\begin{array}{cccc}\text { Schools } & \Delta \text { Wt }(\mathrm{kg}) & \Delta \operatorname{Tr}(\mathrm{mm}) & \Delta \mathrm{HRex}(\mathrm{bpm}) \\ \text { A } & -1.3^{*} & -4.4^{*} & -5.2^{*} \\ \text { B } & +0.8 & -0.9 & 0 \\ \text { C } & -0.5 & -0.2 & -0.2\end{array}$

Vigorous recreational aerobic exercise for 25 minutes a day vigorous recreational aerobic exercise for 25 minutes a day heart rate response to exericse in obese school children that was not seen in matched control groups who received no exercise.
11 EARLY SUCKLING AND PROLONGED BREAST-FEEDING, Pau1 M. Taylor, Judith A. Maloni, David R. Brown, Univ. of f Pediatrics, Pittsburgh, PA Pediatrics, Pittsburgh, PA
We examined the hypothesis that suckling during the first hours of life would be associated with prolonged breast-feeding. We determined the age of complete weaning for 362 infants who were delivered vaginally without general anesthesia. The timing of first extended physical contact with the infant and of first suckling was at the mother's choice. Ninety-five infants did not have extra physical contact in the recovery room, 81 were held at length within the first 90 minutes but not suckled, and 186 were both held and suckled within the first 90 minutes.

\begin{tabular}{|c|c|c|c|c|c|}
\hline & $\mathrm{N}$ & $3 \mathrm{mo}$. & 6 mo. & & $12 \mathrm{mo}$. \\
\hline Not held (NH) & $\overline{95}$ & $\overline{77}$ & 47 & $\overline{31}$ & 4 \\
\hline Held, not suckled (HNS) & 81 & 64 & 46 & 22 & 11 \\
\hline Held and suckled (HS) & 186 & 87 & 69 & 50 & 32 \\
\hline
\end{tabular}

The median age at weaning was 5 months for $\mathrm{NH}$ and HNS infants and 9 months for HS infants. Breast-feeding persisted significantly longer for HS than for either HNS pairs $\left(x^{2}=22.54 ; p<.001\right)$ or NH pairs $\left(x^{2}=16.61 ; p<.001\right)$. Early holding without suckling was not associated with prolonged breast-feeding (HNS vs. NH : $x^{2}=.48$; NS). The association between early suckling and prolonged breast-feeding was not affected by parity or gender. The association between early suckling and prolonged breast-
feeding may be mediated by attitudes and convictions that led mothers to suckle early or (and) by the act of early suckling.
116 TIC SYMPTOMS: BEHAVIORAL CORRELATES Raymond A. Sturner, Sandra G. Funk, Randal D. France, \& J. David-Jones
(Spon. by S.L. Katz), Dept. of Peds., Duke U. Med. Ctr (Spon. by S.L. Katz), Dep

Tourette Syndrome (TS) has been considered to be rare (0.1-0.5/ 1000 ) and is defined (DSM-3) as distinct from the more common Transient Tic Disorder (TTD) because of the occurrence of both vocal and motor components, waxing and waning course, and duration of more than one year. Additionally, TS has been associated with a variety of clinical problems (attention deficit disorder, learning handicaps, speech problems, and secondary social maladjustment) not known to be associated with TTD. We compared kindergarten children whose parents reported (questionnaires \& interviews) that they were very concerned about motor and/or vocal tics [N=14] to other children [N=297] wi thout such reported behavior. The tic report cases were rated as significantly ( $p<.001)$ more hyperactive on the parent Connor's Hyperkinesis Index. These children were found to be significantly $(p<.05)$ lower than other children on 4 of 5 teacher ratings (attention span, learning ability, sociability, and self-esteem), but did not differ on the outgoing/withdrawn item. The teachers were always blind to our hypothes is and to classification based on parent report. They were no different on speech or achievement testing. Interviews revealed a positive family history of tics in $50 \%$ of tic report cases but in only $17 \%$ of a control group $(\mathrm{N}=24)$. In all 9 cases in which 2 years ' follow-up interviews were obtained, symptoms were found to meet the DSM-3 criterion for TS, albeit usually mild. We conclude that TS is probably more common than previously believed. TS probably is

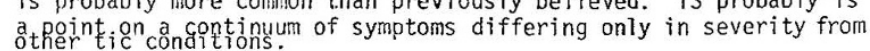

117 PREDICTION OF EARLY SCHOOL PERFORMANCE. Raymond A.

117 Sturner, Sandra G. Funk, \& James A. Green (Spon. by S. This study compares observations embedded during a health procedure (START), a developmental screening test (DDST), and an IQ test (Stanford-Binet) as preschool predictors of school performance.

The START nrocedure is a method in which standard vision acuity procedures are altered so that the approach to testing can be modified based on the child's level of understanding and so that behavioral responses can be quantified without prolonging the procedur itself. Our previous research has consistently demonstrated that prediction of concurrent developmental status is as good or better than that achieved by extensive developmental tests designed exclusively for assessing development. We have also demonstrated that the strictly visual acuity component is more cost-effective that the strictly visual acuity component is more cost-effective than standard acuity screening

A county-wide cohort of prekindergarten children $(\mathrm{N}=382)$ were screened using START and a parent report (GD-45). A stratified sample, $(N=120)$ based on the GD-45 results with oversampling of low scores, was recalled and tested with the DDST and the StanfordBinet. Followup school data were obtained for all children in $\mathrm{K}$ and ist grade. START screening was found to correlate with achievement testing (.50 to .58) better than the Stanford-8inet ( .35 to ment testing ( Clinical indices predicting poor school outcome (failure and/or special placement and/or achievement test results $<20$ th \%il) were all slightly better from START than from the DDST and substantially better than obtained from IQ scores: (e.g. sensitivity of $.64, .57$, and .37 respectively)
RELATIONSHIP BETWEEN MATERNAL AND PERINATAL FACTORS

119 AND OUTCOME OF VERY LOW BIRTHWEIGHT INFANTS. Annabel Univ. of so. Calif. Sch. of Med., LAC-USC Med Ctr, $\frac{\text { Teberg, }}{\text { Dept. of Peds. }}$ 67 infants with $\mathrm{BW}<1501$, born Jan.-Dec. 1982, were evaluated neurobehaviorally at conceptual age $40 \mathrm{wks}$ (term) and neurodevelopmentally at 40 wks age corrected for prematurity (CCA). The relationship between maternal, perinatal factors and infant outcome were evaluated. Results: A) Term: (58 infants) neurobehaviorally, $33(57 \%)$ were normal, $19(\overline{33 \%)}$ were suspect, and 6 (10\%) were abnormal. B) 40 wks CCA: (58 infants) 36 (62\%) were normal neurodevelopmental $\overline{\mathrm{ly}}, 10(178)$ were suspect and $12(218)$ were abnormal developmentally and/or neurologically. The only maternal and obstetrical factor that was significantly $(\mathrm{p}<.01)$ correlated with poor outcome and only at term was lack of prenatal care. Significant neonatal factors at term and 40 wks CCA were:

\begin{tabular}{lccccl} 
& \multicolumn{2}{c}{ Term } & \multicolumn{3}{c}{40 Week CCA } \\
& Normal (33) & Abnormal (6) & Normal (36) & Abnormal (12) \\
Apnea & $52 \%$ & 1008 & 448 & 928 & $\mathrm{p}<.02$ \\
Vascular Prob. & 428 & $1008 \mathrm{p}<.05$ & 428 & 1008 & $\mathrm{p}<.001$ \\
TVH & $18 \%$ & $678 \mathrm{p}<.05$ & $11 \%$ & $58 \%$ & $\mathrm{p}<.01$ \\
Seizure & 128 & $678 \mathrm{p}<.02$ & 88 & $58 \%$ & $\mathrm{p}<.01$
\end{tabular}
Infants with abnormal outcome remained on the ventilator and in the nursery for longer periods, were more immature and lower BW. In summary, the severity of the nursery course in the very low $\mathrm{BW}$ infants rather than maternal and obstetrical factors was found to be related to neurodevelopmental outcome at term and 40 weeks $\mathrm{CCA}$.

120 IMPAIRED COGNITIVE FUNCTION AT AGE 7 YEARS AND 120 OTITIS MEDIA WITH EFFUSION (MEE) DURING THE FIRST YEARS OF LIFE: A PROSPECTIVE, LONGITUDINAL STUDY David W. Teele, Cynthia Chase, Jerome 0. Klein, Bernard Rosner, $\&$ The Greater Boston Collaborative Otitis Media Study Group Boston City Hospital, Dept. of Pediatrics, Boston, Mass.

We measured cognitive function using WISC-R in $1007 \mathrm{y.o}$. We measured cognitive function using WISC-R in $1007 \mathrm{y} \cdot 0$.
children randomly selected from a cohort of consecutively enrolled children followed prospectively from birth. We measured time spent with MEE during each of the first 3 years of 1 ife and determined socioeconomic status (SES) with the Hollingshead 2-factor method. After controlling for SES multiple regression analysis indicated that time spent with MEE during the first 3 years of life was significantly associated with lower verbal and nonverbal scores. (Full-Scale IQ,

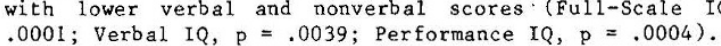

\section{FULL-SCALE IQ}

Days spent with MEE in first three years

Low SES $\quad 109.3(17) * \quad 106.7(17) \quad 99.2(18)$

High SES $\quad 116.9$ (17) 108.9 (14) 103.1 (17)

* mean score (no. children in each group)

Otitis media with effusion occurring in infants is associated with diminished intellectual ability in school-age children. 